\title{
A research on the recycling rate of discarded clothes by structural equation modeling_taking colleges in Beijing as examples
}

\author{
Jie Guan ${ }^{1, a}$, Zhanzhi Zheng ${ }^{1, b}$ \\ ${ }^{1}$ School of Economics and Management, Beijing Jiaotong University, Beijing, 100044,China \\ a15241005@bjtu.edu.cn, b15241179@bjtu.edu.cn
}

Keywords: discarded clothes; recycle rate; structural equation modeling; college students in Beijing.

\begin{abstract}
Recently, the number of discarded clothes is growing sharply in China. This study explores the factors that might influence the recycle behavior of college students by structural equation modeling. Then we establish the structural equation modeling to study the multivariate coupling relationship between recycling behavior and various factors, taking the data from questionnaire of colleges in Beijing as the research sample to make an empirical analysis. The empirical analysis results show that: (1) Environment Knowledge, Personal Consumption Concept and Subjective Norms have positive impacts on the recycle behavior of discarded clothes. (2) The importance of three factors is sorted like this: Subjective Norms > Personal Consumption Concept $>$ Environment Knowledge. At the end of the paper, sensible suggestions are put forward.
\end{abstract}

\section{Introduction}

Discarded clothes have long been the center of public attention. With the rapid development of China's economy in recent years, people incline to change their clothes in an incremental rate. As a consequence, the problem of discarded clothes becomes more severe over time, which leads to resource scarcity and environmental contamination. According to the statistics of China Association of Circular Economy in 2017, the total amount of discarded clothes in China is more than 20 million tons per year while the recycling rate is less than $1 \%$. The primary means of disposal are landfill and incineration. However, some harmful materials attached to clothes often exert an irreparable adverse impact on environment. In fact, only a small number of discarded clothes are utilized again by professional recycling companies or non-profit social organizations. They are donated or processed into industrial materials after certain screening. In conclusion, the current situation of discarded clothes needs more public attention. It's urgent to increase the recycling rate of discarded clothes for the purpose of a long-term interaction between mankind and natural environment.

In order to increase the recycling rate of discarded clothes, it's essential to make clear what factors might affect the recycling rate. The recycling rate refers to the ratio of the parts that can be recycled and the parts that have been already recycled of the waste products. Many factors might have an impact on it, such as personal consumption concept, environmental knowledge, subjective norms and so on. Up to now, domestic and overseas scholars have already done significant researches. Nevertheless, there are few researches focusing on the discarded clothes of college students in China.

The aim of this paper is to explore the possible influential factors of recycling efficiency by structural equation modeling and then put forward several reasonable suggestions, which has a practical significance to the whole society.

\section{Review of literature and theoretical framework}

For the sake of the pertinence of research conclusions, this paper mainly takes college students in Beijing as the object of the research. There are four reasons: (1) Up to now, there are few studies focused on the recycle behavior of college students. (2) College students are the mainstream of the future society, so their 
consumption habits and consciousness are highly representative and forward-looking. (3) College students prefer to follow the latest trend in fashion. They purchase new clothes and obsolete old clothes frequently. As a result, it is practical to take them as the main object of the research. (4) The research is based in the region of Beijing, which will be more convenient for researchers to conduct questionnaire surveys.

On the base of analysis and study of existing research results from home and abroad, the paper assumes that personal consumption concept, environmental knowledge and subjective norms to be potential influential factors.

\section{A. Personal consumption concept}

The concept of personal consumption refers to the guiding ideology and attitude towards their disposable income and the orientation of pursuing the value of commodities of college students. It is the consumers' cognitive embodiment of consumption behavior, consumption object and consumption style. It may indirectly affect the subsequent behavior of consumption, namely recycling behavior. Bianchi $\mathrm{C}^{[1]}$ found that consumer's cognition of discarded clothes would influence their recycling behavior. When Ming $\mathrm{Ni}^{[2]}$ and others study the influencing factor over the recycling acts about the discarded phones, they spread out personal consumption concept based on the following aspects: taking part in the recycling can reduce the environmental pollution, the waste of resources and the improvement of self-responsibility. At the same time, many scholars found that the more positive is the personal consumption concept of waste, the greater is the impact on recycling behavior.

\section{B. Environmental knowledge}

Environmental knowledge refers to how much do public understand the basic situation of the environment and the relevant information of environmental protection. Saripah Abdul Latif ${ }^{[3]}$, Saphores J-D $\mathrm{M}^{[4]}$ and others considered environmental factors as important factors that can affect consumer recycling behavior. When Fumao $\mathrm{Yu}^{[5]}$, Limei $\mathrm{Hu}^{[6]}$ and others studied the influence of situational factors on waste recovery, they found that environmental knowledge can regulate the recovery behavior of electronic waste and used household appliances through investigating a large number of urban residents. Zhanfeng Chen ${ }^{[7]}$ and others have shown that environmental knowledge can influence recycling behavior indirectly by influencing behavior attitude. After studying the recovery behavior of PET bottles in Beijing residents, Zhang Hua ${ }^{[8]}$ got the conclusion that improving public environmental protection knowledge can effectively improve the recovery rate of beverage bottles. In conclusion, a large number of scholars show that environmental knowledge will have a positive impact on the recovery of waste materials. So this paper takes environmental knowledge as one of the influential factors when exploring the recycling of discarded clothes.

\section{Subjective norms}

Subjective norms refer to the social pressure that an individual feels about whether to take a particular act, such as the theory of planned behavior. The Theory of Planned Behavior (TPB) believed that subjective norms can change behavior by influencing behavior intention. The more support important persons give, the larger the behavior intention is, and the practical acts will become more prominent. A great number of scholars regard subjective norms as one of the factors that affect recycling behavior. When Joung, H. M ${ }^{[9]}$ investigated 232 college students, he found that family subjective norms would influence environmentally motivated resale and donation behaviors. In China, the researches on recycling of used household appliances, electronic wastes, used mobile phones and other waste materials has proved that subjective norms are one of the hypothetical factors, but the conclusions are not the same for the past few years ${ }^{[10,11]}$. That is, subjective norms have different effects on the recovery of different waste materials. On the basis of previous studies, this paper further explores the impact of subjective norms on the recycling behavior of discarded clothes. 


\section{Theoretical framework}

On the basis of summarizing previous studies, we explored environment knowledge, personal consumption concept and subjective norms as the influential factors when exploring the Recycle behavior of discarded clothes. More importantly, we should not only clarify what indicators the index system is composed of, but also determine the relationship between indicators. Therefore, we put forward the model frame (Fig1) and the research hypothesis (Table 1).

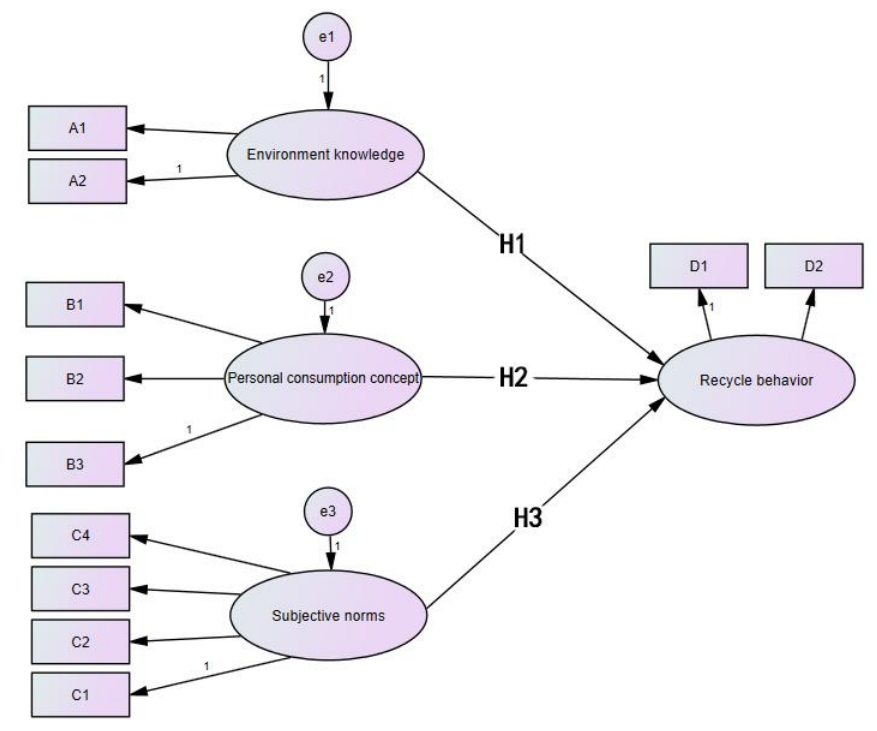

Fig 1 Recycle behavior evaluation model

Table1 Summary of research hypothesis

\begin{tabular}{c|c|c}
\hline $\begin{array}{c}\text { Serial } \\
\text { number }\end{array}$ & Hypothesis & $\begin{array}{c}\text { Expected } \\
\text { symbol }\end{array}$ \\
\hline $\mathrm{H} 1$ & $\begin{array}{c}\text { Environment knowledge has } \\
\text { positive impact on Recycle behavior. }\end{array}$ & + \\
\hline $\mathrm{H} 2$ & $\begin{array}{c}\text { Personal consumption concept has } \\
\text { positive impact on Recycle behavior. }\end{array}$ & + \\
\hline $\mathrm{H} 3$ & $\begin{array}{c}\text { Subjective norms have positive } \\
\text { impact on Recycle behavior. }\end{array}$ & + \\
\hline
\end{tabular}

\section{Verification of recycle behavior evaluation model}

\section{A. Survey Design}

This study uses the method of questionnaire to verify the theoretical model. The survey variables are set up mainly by the above situation. All survey variables are in the form of the Likert five scales, and survey variables are shown in Table 2. In this study, a random sample survey method was used to distribute questionnaires and obtain research data. At last, we collected 382 questionnaires, excluding all the same answers, missing values and invalid questionnaires of non-Beijing universities. A total of 311 valid questionnaires were obtained. Therefore, the sample recycle rate is $86.61 \%$. The subjects covered more than 
12 colleges such as Beijing Jiaotong University, Tsinghua University, Peking University, Renmin University of China and so on. The formal questionnaire is composed of three parts. The first part is the purpose of the survey. The second part is the basic statistical information, including gender, age, grade and so on, and the third part is the specific problem designed according to the measure item.

Table2 Survey variables

\begin{tabular}{|c|c|c|}
\hline Variables & $\begin{array}{c}\text { Survey } \\
\text { variables }\end{array}$ & Contents of survey variables \\
\hline \multirow[b]{2}{*}{$\begin{array}{l}\text { Environment } \\
\text { knowledge }\end{array}$} & A1 & $\begin{array}{l}\text { There are environmental courses or lectures in the } \\
\text { school. }\end{array}$ \\
\hline & $\mathrm{A} 2$ & $\begin{array}{l}\text { The school has organized environment protection } \\
\text { activities or established environment protection } \\
\text { organizations. }\end{array}$ \\
\hline \multirow{3}{*}{$\begin{array}{l}\text { Personal } \\
\text { consumption } \\
\text { concept }\end{array}$} & $\mathrm{B} 1$ & $\begin{array}{l}\text { Participation in recycling can reduce environmental } \\
\text { pollution. }\end{array}$ \\
\hline & $\mathrm{B} 2$ & $\begin{array}{l}\text { Participation in recycling can reduce the waste of } \\
\text { resources }\end{array}$ \\
\hline & B3 & $\begin{array}{l}\text { Participation in recycling reduces the cost of social } \\
\text { recycling }\end{array}$ \\
\hline \multirow{4}{*}{$\begin{array}{l}\text { Subjective } \\
\text { norms }\end{array}$} & $\mathrm{C} 1$ & Friends have an impact on taking part in recycling. \\
\hline & $\mathrm{C} 2$ & $\begin{array}{l}\text { The government has an impact on taking part in } \\
\text { recycling. }\end{array}$ \\
\hline & $\mathrm{C} 3$ & Schools have an impact on taking part in recycling \\
\hline & $\mathrm{C} 4$ & $\begin{array}{l}\text { Social environment protection propaganda has an } \\
\text { impact on taking part in recycling. }\end{array}$ \\
\hline \multirow{2}{*}{$\begin{array}{l}\text { Recycle } \\
\text { behavior }\end{array}$} & D1 & $\begin{array}{l}\text { You have been involved in the recovery of discarded } \\
\text { clothes for the past year. }\end{array}$ \\
\hline & D2 & $\begin{array}{l}\text { You will be involved in the recovery of discarded } \\
\text { clothes in the next half of the year. }\end{array}$ \\
\hline
\end{tabular}

\section{B. Questionnaire collection}

- Statistical analysis

A Cronbach's a-value was utilized to measure the confidences between the measurement variables that were considered highly correlated, thereby estimating the internal consistency reliability ${ }^{[12]}$. Table 4 shows Cronbach's a-value within the factors considered in the study. Since all of the factors indicated values over 0.7 , the confidences of the measurement variables utilizing the questionnaires were assumed to be sufficient ${ }^{[12]}$. It is therefore implied that the latent variables, which are impossible to measure directly, are actually possible to measure in an indirect way. 
Table3 Cronbach's a-value of latent variable and measurement variable.

\begin{tabular}{c|c|c}
\hline Latent variable & $\begin{array}{c}\text { Numbers of } \\
\text { measurement variable }\end{array}$ & Cronbach's a \\
\hline Environment knowledge & 2 & 0.717 \\
\hline Subjective norms & 4 & 0.838 \\
\hline Personal consumption concept & 3 & 0.870 \\
\hline Recycle behavior & 2 & 0.727 \\
\hline
\end{tabular}

- Reliability analysis

To verify the reliability of the recycle behavior model on latent variables, the latent variables determined by the observed variables were examined through an analysis of composite reliability and construct validities. The composite reliabilities were indicated to be over 0.7 . Table 5 shows the construct validities (criteria over 0.7) and Average Variance Extracted (AVE, criteria over 0.5) ${ }^{[13]}$. All the AVE of ambient factors and seat factors is over 0.5 , which shows the high credibility of the model.

Table4 Construct reliability and Average Variance Extracted

\begin{tabular}{c|c|c}
\hline Factors & $\begin{array}{c}\text { Construct } \\
\text { reliability }\end{array}$ & AVE \\
\hline Environment knowledge & 0.7223 & 0.5674 \\
\hline Subjective norms & 0.8692 & 0.689 \\
\hline Personal consumption concept & 0.8406 & 0.5706 \\
\hline
\end{tabular}

\section{Analysis of structural equation modeling}

Based on the results of the questionnaire, the latent variables and their measurement variables in Table 2 are analyzed. The results of AMOS21.0 shows that the final fitting results of structural equation models were shown in Table 5.

Table5 Fit statistics for SEM

\begin{tabular}{|c|c|c|c|c|c|}
\hline Index & CMIN & DF & CMIN/DF & GFI & RMSEA \\
\hline Standard & & & If $<3$, accept & If $>0.90$, accept & If $<0.80$, accept \\
\hline Results & 113.545 & 42 & 2.703 & 0.94 & 0.074 \\
\hline Index & AGFI & NFI & RFI & NNFI & CFI \\
\hline Standard & $\begin{array}{c}\text { If }>0.90 \\
\text { accept }\end{array}$ & $\begin{array}{c}\text { If }>0.90 \\
\text { accept }\end{array}$ & $\begin{array}{c}\text { If }>0.90 \\
\text { accept }\end{array}$ & $\begin{array}{c}\text { If }>0.90 \\
\text { accept }\end{array}$ & $\begin{array}{c}\text { If }>0.90 \\
\text { accept }\end{array}$ \\
\hline Results & 0.906 & 0.929 & 0.906 & 0.939 & 0.963 \\
\hline
\end{tabular}


By analyzing the recycle behavior model with SEM, the fitness indexes shown in Table 6 are generated. The results show that both the fitness of the recycle behavior model and that of the path value were significant in the confidence range of $90 \%$. To review only the fitness indexes, the indexes of GFI (0.940) and AGFI (0.906) had values that were in the significant level. RMSEA (0.074) and NFI (0.929) were also in the significant range, thus the model itself was judged to be acceptable ${ }^{[14]}$.

Then we construct the normalized recovery behavior structural equation model path diagram, as shown in Figure 2.

Fig2 The normalized path diagram of the recycle behavior model

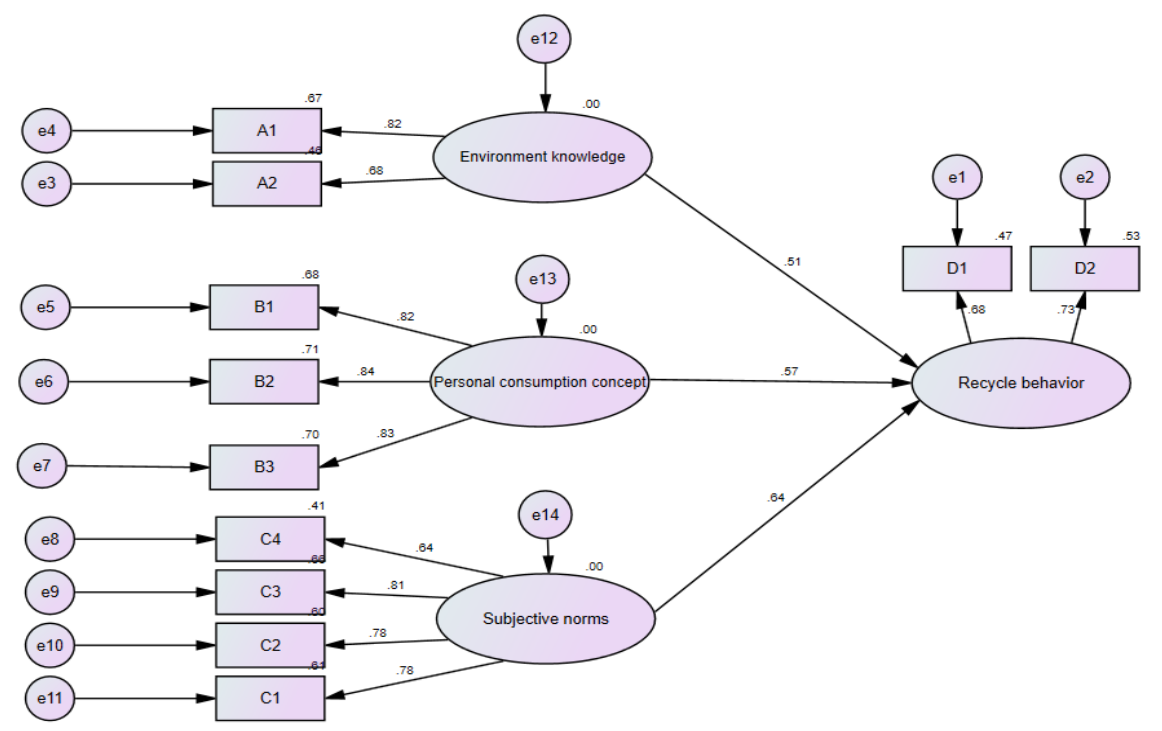

The results of the factor loading about the latent variables and the measurement variables are shown in Table 6. The results of hypothesis tests are shown in Table7.

Table6 Completely standardized parameter estimates and factor loading

\begin{tabular}{c|c|c|c|c|c}
\hline & Estimate & S.E. & C.R. & P & $\begin{array}{c}\text { Factor } \\
\text { loading }\end{array}$ \\
\hline Environment knowledge $\rightarrow \mathrm{A} 1$ & 1 & & & & 0.681 \\
\hline Environment knowledge $\rightarrow \mathrm{A} 2$ & 1.272 & 0.168 & 7.568 & $* * *$ & 0.817 \\
\hline Personal consumption concept $\rightarrow \mathrm{B} 1$ & 1 & & & & 0.835 \\
\hline Personal consumption concept $\rightarrow \mathrm{B} 2$ & 0.898 & 0.055 & 16.264 & $* * *$ & 0.842 \\
\hline Personal consumption concept $\rightarrow \mathrm{B} 3$ & 0.98 & 0.062 & 15.909 & $* * *$ & 0.822 \\
\hline Subjective norms $\rightarrow \mathrm{C} 1$ & 1 & & & & 0.783 \\
\hline
\end{tabular}




\begin{tabular}{c|c|c|c|c|c}
\hline Subjective norms $\rightarrow \mathrm{C} 2$ & 1 & 0.074 & 13.586 & $* * *$ & 0.778 \\
\hline Subjective norms $\rightarrow \mathrm{C} 3$ & 1.073 & 0.076 & 14.122 & $* * *$ & 0.81 \\
\hline Subjective norms $\rightarrow \mathrm{C} 4$ & 0.864 & 0.079 & 10.961 & $* * *$ & 0.637 \\
\hline Recycle behavior $\rightarrow \mathrm{D} 1$ & 1 & & & & 0.683 \\
\hline Recycle behavior $\rightarrow \mathrm{D} 2$ & 1.176 & 0.105 & 11.237 & $* * *$ & 0.727 \\
\hline
\end{tabular}

Table7 Results of hypothesis tests

\begin{tabular}{c|c|c|c|c}
\hline & Symbol & $\begin{array}{c}\text { Factor } \\
\text { loading }\end{array}$ & $\mathrm{P}$ & Outcome \\
\hline Environment knowledge $\rightarrow$ Recycle behavior & + & 0.510 & $* * *$ & Supported \\
\hline Personal consumption concept $\rightarrow$ Recycle behavior & + & 0.573 & $* * *$ & Supported \\
\hline Subjective norms $\rightarrow$ Recycle behavior & + & 0.642 & $* * *$ & Supported \\
\hline
\end{tabular}

\section{Conclusions and suggestions}

According to the normalized coefficient in the regression analysis, the importance of the 3 factors is sorted: Subjective norms $>$ Personal consumption concept $>$ Environment knowledge. The analysis of three significant effects is followed:

(1) Environment knowledge has positive impact on discarded clothes' recycle behavior. The more knowledge students have, the more they can improve their express package recycle behavior.

For the school, Environment knowledge can be improved by following ways: Schools should increase the courses on environment protection and environment protection lectures. Environment events related to environment protection should also be held by well-known environmentalists or organizations.

(2)Personal consumption concepts have positive impact on discarded clothes' recycle behavior. The stronger the concepts of personal consumption, the more it can improve the express package of college students' recycle behavior.

For the school, Personal consumption concepts can be improved by following ways: Schools can improve students' concepts of personal consumption through class education and class activities such as holding the environmental protection courses. Schools also should regularly hold seminars about environment protection to improve students' environment protection knowledge and the concept of environment protection.

(3)Subjective norms have positive impact on discarded clothes' recycle behavior and environment knowledge. And Subjective norms have the greatest impact on recycle behavior.

For the government, the school and the college students, Subjective norms can be improved by following ways: Students should be encouraged to have a positive impact on each other so that college students will be more involved in the recycling of discarded clothes. Schools can set up courses related to environment protection, regularly hold lectures related to environment protection, etc., so as to improve the positive influence of school dimensions on College Students' subjective norms. The government can publicize the right values by various propaganda methods such as public service ads, newspapers, WeChat, 
micro-blog and so on. At the same time, the government should publicize the knowledge related to the recycling and reuse of discarded clothes.

\section{References}

[1] Bianchi, C., \& Birtwistle, G. (2012). Consumer clothing disposal behaviour: A comparative study. International journal of consumer studies, 36(3), 335-341.

[2] Ming Ni, Xuebei Yang, Junhua Guo, Shanlin Yang. An empirical study on the influencing factors of Recycling behavior of waste Mobile phones-based on the questionnaire Survey of College students[J]. Journal of Beijing Jiaotong University(SOCIAL SCIENCE EDITION), 2015, 14(3) 89-96.

[3] Saripah Abdul Latif, Mohd Shukri Omar et al, Environmental Values as a Predictor of Recycling Behavior in Urban Areas: A Comparative Study[J]. Procedia - Social and Behavioral Sciences, 2012(50): 989-996.

[4] Saphores J-D M, Nixon H, Ogunseitan O A, et al. Household willingness to recycle electronic waste: an application to California [J]. Environment and Behavior, 2006, 38(2): 183-208.

[5] Fumao Yu. The influence of situational factors on the recycling behavior of discarded household appliances among urban residents[J]. Ecological economy, 2012(2): 137 / 141, 177.

[6] Limei Hu, Fumao Yu. Study on the behavior intention of Consumer Electronic waste Recycling[J]. Journal of Hangzhou University of Electronic Science and Technology: social Sciences, 2012(3)A: 19-24.

[7] Zhanfeng Chen, Jiying Chen, Bin Zhang, Kun Wang, Zhaohua Wang. Analysis of influencing factors on e-waste recycling behavior[J]. Ecological Economy, 2013(2):178-183.

[8] Hua Zhang, Zongguo Wen. Study on consumption and recovery behavior of PET bottles Among Residence in Beijing [J]. Renewable Resources and Recycling economy, 2014,7(5): 19-22.

[9] Joung, H. M., \& Park - Poaps, H. (2013). Factors motivating and influencing clothing disposal behaviours. International Journal of consumer studies, 37(1), 105-111.

[10] Yongqing Liu, Qingming Gong, Yirun Hu. Research on the evaluation system of the factors influencing the recycling of used household appliances by consumers[J]. Ecological Economy, 2015, 31(5):108-110.

[11] Chang Wang, Xiabing Lu, Qiao Sun. Research on the factors influencing residents' participation willingness of "internet plus recycling" [J]. Chinese Journal of Management, 2017(12):1847-1854.

[12] Chen Sheng Ke.SPSS statistical analysis from entry to mastery [M]. Beijing: Tsinghua University press, 2013.

[13] HAIR JF, ANDERSON RE, TATHAM RL, et al. Multivariate Data Analysis [M]. New Jersey: Prentice-Hall International, 2010

[14] Wu Minglong. Structural equation modeling -- the operation and application of AMOS [M]. Chongqing: Chongqing University press, 2016. 